\title{
Celso Furtado e Raúl Prebisch frente à crise do desenvolvimentismo da década de 1960
}

\author{
Celso Furtado and Raúl Prebisch in the face of the crisis of developmentalism of \\ the 1960s
}

Fágner João Maia Medeiros e Daniel do Val Cosentino*

\begin{abstract}
Resumo: Os anos de 1960 marcam uma profunda crise no pensamento desenvolvimentista na América Latina. O projeto de industrialização, conforme teorizado pelos estruturalistas da CEPAL, demonstra sua inviabilidade na reversão do subdesenvolvimento. Em vista disso, em busca de compreender como dois renomados intelectuais expoentes do desenvolvimentismo interpretam tal crise, o estudo assume por objetivo identificar aproximações e distanciamentos entre $\mathrm{o}$ pensamento desenvolvimentista de Raúl Prebisch e Celso Furtado posteriores à Crise do Pensamento Desenvolvimentista dos anos de 1960 na América Latina. Apesar de enfoques distintos, tais autores presenciam com a crise uma tomada de consciência. Desse modo, surge a necessidade de compreender a estrutura social da região e os seus mecanismos que atuam entorpecendo o desenvolvimento.
\end{abstract}

Palavras-chave: América Latina; Subdesenvolvimento; Crise do Desenvolvimentismo; Raúl Prebisch; Celso Furtado

\begin{abstract}
The 1960's mark a profound crisis in the development thinking in Latin America. The industrialization project, according to the theory elaborated by structuralists of ECLAC (or CEPAL), demonstrates its inviability on the reversal of underdevelopment. In view thereof, seeking to understand how the two renowned intellectual exponents of development interpret the crisis, the study assumes as its objective to identificate approximations and retraction in the theory formulated by Raúl Prebisch and Celso Furtado after the Crisis of Development Thinking in Latin America during the 1960's. Despite different approaches, these authors observe the emergence of the necessity to understand the social structure of the region of understand the social structure of the region and its mechanism that acts numbing development.
\end{abstract}

Keywords: Latin America; Underdevelopment; Crisis of Developmentalism; Raúl Prebisch; Celso Furtado

JEL Code: B29; B30; N01

\footnotetext{
* Respectivamente, mestrando em Desenvolvimento Econômico pelo Instituo de Economia da Universidade Estadual de Campinas (IE/Unicamp). E-mail: fagnerjmaia@gmail.com. Orcid: https://orcid.org/00000003-0366-8535; e professor da Universidade Federal de Ouro Preto (UFOP). E-mail: dcosentino@terra.com.br. Orcid: https://orcid.org/0000-0002-5891-6594.
} 


\section{Introdução}

Raúl Prebisch ao lado de Celso Furtado foram renomados economistas latino-americanos com grande impacto intelectual e ideológico no que se refere ao desenvolvimento da América Latina. Tais autores colaboraram com a construção de um pensamento original e duradouro, que lhes permitiu figurar como expoentes do estruturalismo latino-americano.

No pós-guerra, sobretudo, com a criação da Comissão Econômica para América Latina e o Caribe (CEPAL), as discussões relacionadas ao subdesenvolvimento da América Latina recebem centralidade, aglutinando por grande parte das camadas sociais uma ideologia que objetiva a superação do subdesenvolvimento: o desenvolvimentismo. Nesse período, Prebisch e Furtado foram arquitetos do desenvolvimentismo dentro da CEPAL; Prebisch por questionar incisivamente as teorias do comércio internacional prevalecentes na época, inferindo que o comércio internacional - sob as rédeas de uma Divisão Internacional do Trabalho - atuava dividindo o mundo em dois extremos, no que tange ao nível de renda e à produtividade, isto é, havia uma divisão centro-periferia (PREBISCH, 2011). Furtado, por sua vez, por desafiar as formulações dos clássicos da Teoria do Desenvolvimento que tratavam o subdesenvolvimento como uma questão evolutiva, ou de etapas superadas ${ }^{1}$. O subdesenvolvimento na percepção de Furtado seria então um fenômeno de nítido fator histórico, no qual não há etapas históricas comuns entre os países, mas uma condição específica do resultado da evolução do desenvolvimento capitalista (FURTADO, 2009).

Desse prisma, havia uma convergência teórica e metodológica no pensamento de ambos os autores, e o cerne desse pensamento sinalizava para a necessidade de um projeto de industrialização, comandado deliberadamente pelo Estado, como única via de superação do subdesenvolvimento da região. Na década de 1950, tal projeto se concretizou como apoio à intensificação da industrialização por substituição de importações (ISI), já praticado por alguns países latinoamericanos desde a grande depressão de 1930. O sucesso desse projeto era identificado pelas elevadas taxas de crescimento que vigoraram ao longo da década, e por profundas transformações na estrutura produtiva da região. Entretanto, na década de 1960, uma crise marca o esgotamento desse processo,

\footnotetext{
${ }^{1}$ A obra de Rostow, As etapas do Desenvolvimento Econômico (1974), refletia a visão que prevalecia na literatura da época.
} 
uma vez que a industrialização estava sendo acompanhada pelo avanço da marginalização e do desemprego. É importante aqui entender que tal crise sobrepõe efeitos ao lado real e monetário da economia, pois se desdobra em uma crise teórica. Em outros termos, havia uma crise no pensamento desenvolvimentista.

A crise do desenvolvimentismo emergia juntamente com as contradições do modelo formulado pela Cepal. A industrialização, por si só, demonstrava não ser capaz de criar condições para a superação do subdesenvolvimento na América Latina. No campo das ideias, o contexto impõe ao pensamento uma encruzilhada. Este artigo procura compreender as interpretações de Celso Furtado e Raúl Prebisch desse processo diante do ambiente de crise e os desdobramentos teóricos de tais reflexões.

De acordo com Lessa (2005), esse momento representa um ponto de inflexão no pensamento de Furtado - o mesmo pode ser pensado para Prebisch -, uma vez que o autor passa a se dedicar na compreensão de como a periferia não foi capaz de reproduzir os padrões de vida do centro.

Ambos os autores têm conclusões semelhantes com respeito à crise, apontando a necessidade de promover intensas reformas estruturais especialmente na estrutura da renda e da terra - para continuidade do processo de desenvolvimento. Contudo, é possível notar que o ponto de partida dos dois diverge: enquanto Prebisch tem sua atenção direcionada à problemática do desemprego estrutural (PREBISCH, 1968), Furtado verifica na crise uma tendência à estagnação no processo de industrialização com a implementação do setor de bens de consumo duráveis e bens de capitais (FURTADO, 1968). Assim, este texto tem como propósito também identificar aproximações e distanciamentos entre o pensamento de Raúl Prebisch e Celso Furtado diante da crise dos anos de 1960 na América Latina.

Desse modo, analisamos neste trabalho Dialética do Desenvolvimento (1964) e Subdesenvolvimento e Estagnação na América Latina (1968 [1966]), de Furtado; e Dinâmica do desenvolvimento latino-americano (1968 [1963]); Transformação e Desenvolvimento (1973 [1970]), de Prebisch, obras nas quais os autores procuram interpretar a crise dos anos de 1960 e sugerir soluções teóricas para a encruzilhada desenvolvimentista. Para tanto, este trabalho foi estruturado em quatro seções para além desta introdução: (i) crise do pensamento 
desenvolvimentista da década de 1960; (ii) Raúl Prebisch e crise de insuficiência dinâmica; (iii) Celso Furtado e a tendência inexorável a estagnação; por fim, são apresentadas as (iv) considerações finais, retomando as principais observações das seções anteriores, bem como ilustrando as diferenças e similaridades entre dois dos mais relevantes nomes do estruturalismo latino-americano: Celso Furtado e Raúl Prebisch.

\section{A crise do pensamento desenvolvimentista da década de 1960}

Na América Latina, o projeto de industrialização praticado ao longo do pósGuerra logrou um ciclo expansivo que promoveu transformações radicais na estrutura econômica-social da região. Tendo o Brasil como exemplo², Serra (1998) aponta que o êxito de tal projeto supera as elevadas taxas de crescimento combinadas com níveis suportados de inflação apresentadas ao longo do período. Havia também no Brasil uma modificação na composição da estrutura econômica, pois a participação da agricultura reduziu significativamente no PIB, passando de $24,9 \%$ no ano de 1949 para 19,2\% em 1959. Já o setor industrial traçou o caminho inverso, adquirindo um considerável protagonismo, passando no mesmo período de $26 \%$ para $32,6 \%$. No caso do setor externo, houve um notável "fechamento" da economia no que se refere às importações e, em contrapartida, uma evidente diversificação da pauta de exportações.

Tais modificações expostas acima fizeram parte das propostas de pensadores como Raúl Prebisch e Celso Furtado. Ambos foram expoentes do desenvolvimentismo e contribuíram, ao longo da década de 1950, tanto com suporte teórico quanto na produção de relatórios para orientação dos policy makers de toda América Latina a partir da CEPAL. Não obstante, o cenário se reverte na década seguinte. Conforme Bumer-Thomas (2000), a taxa de crescimento deixou de ser satisfatória para muitos dos países em processo de industrialização, além disso, ocorreram problemas de cunho econômico, social e até mesmo, para alguns países, políticos.

A crise da década de 1960 se manifesta primeiramente com a queda dos indicadores econômicos nos países latino-americanos. O crescimento econômico

\footnotetext{
2 Dentre os países da América Latina, o Brasil, o México e o Chile são os países que, de certa forma, inicialmente receberam maiores influências da CEPAL (BIELSCHOWSKY, 2000a).
} 
entre 1960 e 1964 na América Latina cai para apenas 0,3\% ao ano, acompanhado da elevação das taxas de desemprego e pressões inflacionárias. Ademais, havia o recorrente problema externo, pois desequilíbrios na balança comercial sinalizavam limitações na capacidade de importar, que se constituía em uma condição fundamental para a dinâmica do processo substitutivo (BIELSCHOWSKY, 2000a).

Parece inegável que o início da década de 1960 representa uma ruptura com o ciclo expansivo da fase anterior. Porém, é necessário entender tal crise em seu sentido mais profundo e sob suas diversas faces, isto é, se afastando da mera aparência desse fenômeno. O primeiro passo seria entender o esgotamento da ISI. Rodríguez (2009) explica o evento a partir de uma dupla determinação. Primeiro, é preciso compreender a dinâmica e a evolução do processo substitutivo, realizado em etapas. Após a segunda metade da década de 1950, empreende-se a instalação da indústria pesada: indústria química e metal mecânica, configurando um novo padrão industrial que ampliou drasticamente a necessidade de proteção e a exigência por vultosos investimentos - tanto do setor público quanto estrangeiro na forma de investimento externo direto (IED). Na década de 1960, alguns dos países da América Latina já partiam para uma nova etapa do processo, a implementação do setor moderno, tais como a indústria de bens de capital (BK) e de bens de consumo duráveis (BCD). A composição desses novos setores foi marcada pela participação de transnacionais que faziam uso de tecnologias absorvidas dos grandes centros que apresentavam enormes descontinuidades tecnológicas, sendo marcadas, dessa forma, por um elevado coeficiente de capital e requisitando escalas mínimas de produção que exigiriam um mercado cada vez mais amplo.

Como exposto acima, diferente da instalação das primeiras indústrias (de alimentos e têxtil), a dinâmica do setor moderno era distinta. As indústrias de bens de capital e de consumo duráveis estavam organizadas por oligopólios no comércio internacional. Em razão disso, suas tecnologias eram restritas e seus mercados eram defendidos com elevadas barreiras à entrada. Nesse novo cenário, a resposta dos países latino-americanos foi imediata. Bumer-Thomas (2000) assinala que essa etapa do processo substitutivo havia modificado a posição dos países da América Latina, ditos nacionalistas, com relação ao capital externo. O Brasil e a Argentina, respectivamente, nos anos de 1955 e 1959, modificaram seus marcos legislativos 
favorecendo aspectos vinculados ao capital estrangeiro. Já no caso do México, por um lado, o país assegurou alguns setores para o capital nacional, por outro, reservou para empresas multinacionais outros setores como o de manufatura.

O segundo determinante alude às alterações geopolíticas do período, quando os EUA gradualmente retiraram seus compromissos financeiros para com a América Latina, tendo sua política externa cada vez mais pautada pelo enfrentamento à União Soviética. Desse modo, a Europa e a Ásia se tornavam áreas de maior prioridade. Conforme Pollock (1987), diversos órgãos internacionais ${ }^{3}$ criados no período adotam uma configuração política coincidente com a proposta da CEPAL. Contudo, o agravamento da Revolução Cubana insere a região no mapa da Guerra Fria. A partir de então, a política de segurança dos Estados Unidos passa a comprometer a autonomia dos Estados latinos ${ }^{4}$.

Além disso, o novo panorama da década de 1960 acelera a manifestação das insuficiências do projeto desenvolvimentista. A industrialização formou novos grupos sociais, ampliando pressões sobre o sistema político. Emergem tanto movimentos contestatórios do campo, por não se sentirem inseridos no projeto de desenvolvimento, quanto organizações de trabalhadores nas cidades. Junto a isso, havia o desgaste do protagonismo da burguesia nacional, ao passo em que a industrialização se ancorava, de forma cada vez mais presente, ao capital estrangeiro (BIELSCHOWSKY, 2000a).

Não menos importante, a crise da década de 1960 retirou dos estruturalistas da CEPAL a posição dominante na interpretação do subdesenvolvimento da América Latina. Um grupo de pensadores, intitulado como "teóricos da dependência”, enxergava na crise a necessidade de compreender as limitações do desenvolvimento latino-americano em contraponto às grandes hegemonias, tendo por principais expoentes Ruy Mauro Marini, Fernando Henrique Cardoso, Enzo Faletto e Theotônio dos Santos. De forma geral, esses autores argumentavam que o projeto da CEPAL apenas agravava a condição de subdesenvolvimento ao não se preocupar com problemas resultantes do desenvolvimento capitalista, tais como: exploração, concentração de capital, apropriação privada, entre outros (DUARTE;

\footnotetext{
${ }^{3}$ Como exemplo, foram criados os seguintes órgãos: Operação Pan-Americana (OPA), Aliança para o Progresso e o Banco Interamericano de Desenvolvimento (BID) (RODRÍGUEZ, 2009).

${ }^{4}$ A crise dos mísseis no ano de 1962 dá abertura a uma postura mais agressiva dos EUA com a região. Após o ano de 1964, diversos países do Cone Sul são atingidos por golpes de Estado, dessa forma, acumulando regimes ditatoriais na América Latina (RODRÍGUEZ, 2009).
} 
GRACIOLLI, 2007). Para Carmo Sobrinho (2001, p. 8), esses autores objetivam "superar as insuficiências da teoria da CEPAL e dar conta das especificidades do desenvolvimento capitalista na América Latina". Essa questão não é o ponto central deste trabalho, mas ilustra a evidente existência de uma crise enfrentada pelo pensamento cepalino no plano teórico.

Para Serra (1976), os anos de 1960 se resumem pela erosão do sonho desenvolvimentista, dado que a industrialização perdia seu dinamismo nos países latino-americanos por consequência de contradições e desequilíbrios que ela mesma engendra e, em alguns casos, até mesmo aprofunda. A industrialização manifestava seu esgotamento provocando uma urbanização desenfreada. À medida que as cidades da América Latina se transformavam em grandes concentrações urbanas, problemas como miséria e desemprego foram sendo deslocados do campo para a cidade ${ }^{5}$ Consequentemente, alastrou-se para alguns países da América Latina instabilidade política e conflitos sociais. Assim, tornava-se evidente que apenas uma pequena parcela da população estava se beneficiando dos frutos do desenvolvimento econômico.

À luz desses determinantes, os teóricos da CEPAL percebem que nem mesmo o bom planejamento econômico em favor da industrialização superaria os entraves estruturais da região, seus gargalos econômicos e sociais. Bielschowsky (2000a, p. 409) alerta que essa nova conjuntura se desdobra em uma crise teórica, pois:

(...) ocorreu uma crise no pensamento desenvolvimentista, expressa na literatura de então. O projeto de industrialização planejada, que vinha orientando de forma mais intensa o pensamento dos economistas brasileiros, deixou de ser o núcleo ideológico das propostas e análises econômicas.

Essa conjuntura impôs a necessidade de se pensar alternativas de desenvolvimento e novas interpretações do subdesenvolvimento da América Latina. Prebisch e Furtado, figuras de grande prestígio teórico e que ocupavam postos de planejamento em governos ou em órgãos de desenvolvimento, se viram sob o compromisso de reformular suas concepções e elaborar uma resposta à crise.

\footnotetext{
5 Bulmer-Thomas (2000) afirma que até os anos de 1940, a população pobre se encontrava, substancialmente, nas zonas rurais. Todavia, nos anos de 1960, a proporção de pobres se encontra bem distribuída entre campo e cidade. O reflexo desse crescimento da imigração rural-urbana estava na criação de habitações precárias e empregos informais (subempregos).
} 
Desse modo, enveredam por um receituário reformista ao identificarem um bloqueio estrutural no desenvolvimento da América Latina ${ }^{6}$.

Essa resposta reformista incluía teóricos da CEPAL que apontavam que o desenvolvimento econômico necessita de acompanhamento de profundas modificações no aparato institucional e reformas de base ${ }^{7}$. Bielschowsky (2000b) sublinha que pela primeira vez o cerne do debate econômico tomava rumos distintos, retirando prioridade das preocupações tradicionais do desenvolvimentismo, como comércio, estrutura produtiva, entre outros.

Portanto, diante desse contexto, Prebisch e Furtado se inserem no debate da crise tendo consciência de que precisavam ampliar seu escopo teórico para propor um diagnóstico mais eficaz com respeito ao subdesenvolvimento da América Latina, sem abandonar, entretanto, o método estruturalista. Assim, nas seções seguintes examinaremos a resposta de cada um à crise econômica e teórica ilustrada nos parágrafos anteriores.

\section{Raúl Prebisch e a crise de insuficiência dinâmica}

$\mathrm{Na}$ década de 1960, Prebisch, diante da crise do pensamento desenvolvimentista, propõe um diagnóstico reformista. Nesse período esteve sempre vinculado a algum importante órgão internacional de desenvolvimento. No início da década, dentro da CEPAL e posteriormente no Instituto Latinoamericano de Planificación Económica y Social (ILPES), escreveu Dinâmica do Desenvolvimento Latino-Americano (1968 [1963]), em que propunha um esforço de atualização do seu pensamento, identificando limites no processo de desenvolvimento $^{8}$. A partir do ano de 1964, já como secretário geral da United Nations Conference on Trade and Development (UNCTAD), com sede em Genebra, escreveu Transformação e Desenvolvimento (1973 [1970]),

\footnotetext{
${ }^{6}$ Para uma análise da controvérsia acerca das políticas preconizadas por Prebisch na Argentina e Furtado no México nos anos 1950, ver Fonseca e Salomão (2018).

${ }^{7}$ Bielschowsky (2000a) alerta que a exigência de reformas presente na literatura da época estava vinculada tanto a reformas institucionais, financeiras e tributárias, modificando a modernização do Estado, quanto, e sobretudo, sobre reformas radicais na estrutura da terra e sob a estrutura distributiva.

${ }^{8}$ Ainda no ano de 1961, em sua obra O Falso Dilema entre Desenvolvimento Econômico e Estabilidade Monetária (2011a), na qual Prebisch pretender discutir a questão da inflação. Nesse escrito, o autor defende pela primeira vez de forma clara e precisa a necessidade de reformas de base. Dosman (2011) também mostra que essa guinada reformista no pensamento de Prebisch antecede sua obra do ano de 1963, pois em seu discurso de despedida da Cepal no ano de 1962 levanta novas problemáticas sobre o desenvolvimento da região com crescentes críticas às elites latino-americanas, tocando em temas como: propriedade da terra, distribuição de renda e, até mesmo, educação pública.
} 
apresentando os princípios que norteavam sua nova estratégia de desenvolvimento de cunho reformista.

Gurrieri (2011) identifica nas obras de Prebisch uma dissociação com o programa inicial da CEPAL. Além das críticas aos rumos que tomavam o processo de industrialização substitutiva, passa a englobar outras áreas de conhecimento em sua análise, utilizando posições sociológicas para interpretar a estrutura social latino-americana. Além disso, a teorização de Prebisch tendeu a tomar duas dimensões. De um lado, relacionada ao desequilíbrio externo que assolava os países latino-americanos, e a cooperação internacional como uma ferramenta para conter tal problema. De outro, à existência de estrangulamento interno nas economias da região, que refletia na incapacidade da América Latina em alcançar uma taxa adequada de acumulação, tendo em vista que o capital na região possuía uma utilização incoerente com os propósitos do desenvolvimento.

Com base nessas questões, as observações de Prebisch nos anos de 1960 retiravam o papel passivo da desigualdade social dentro da Teoria do Desenvolvimento, reconhecendo que a "estrutura social predominante na América Latina opõe um sério obstáculo ao progresso técnico, e por conseguinte, ao desenvolvimento econômico e social" (PREBISCH, 1968, p. 12). Tal evidência se manifestava nos seguintes fatores: (i) a estrutura social entorpece a mobilidade social; (ii) a distribuição de renda privilegiada debilita, ou até mesmo elimina, o incentivo à atividade econômica, em detrimento à utilização eficaz do trabalho, do uso da terra e do capital; por último, (iii) o privilégio distributivo se traduz em padrões de consumo exagerados, ao invés de expandir o ritmo de acumulação de capital.

Na percepção de Prebisch, o avanço do processo substitutivo na América Latina demonstrou que a industrialização não seria capaz de corrigir fatores que inibem o desenvolvimento, muito pelo contrário, tal processo estava agravando a dicotomia entre o econômico e o social. Esse desequilíbrio se manifestava em conjunto ao crescimento populacional e a uma tendência à emigração do campo para as cidades, o que ocasionava um tipo de urbanização problemática. Tratavase de um problema estrutural econômico e social da região, pois a propriedade da terra mantinha a renda concentrada no campo e utilizada improdutivamente nas cidades, dessa forma, distorcendo a distribuição geográfica da renda e contribuindo 
para elevação dos níveis de desemprego devido à incapacidade da indústria de absorver toda mão-de-obra ${ }^{9}$ (PREBISCH, 1968).

Como uma proporção sensível do aumento da população ativa não era absorvida no processo produtivo, o desemprego se torna o ponto de partida da teorização do autor, sendo ele, portanto, estrutural ${ }^{10}$. Prebisch (1968) fez uso do conceito de "suficiência dinâmica" como um parâmetro de avaliação do desempenho da economia em seu novo diagnóstico. Dessa forma, a capacidade de absorção produtiva da força de trabalho, não seu nível de crescimento do produto, determinaria o dinamismo de uma economia ${ }^{11}$. Na compreensão de Gurrieri (2011), esse novo conceito representa uma continuidade no pensamento do autor, visto que fatores como geração, distribuição, propagação e o uso do progresso técnico, que anteriormente eram negligenciados, agora são deslocados ao centro do debate.

Diante disso, a América Latina situava-se em uma crise de insuficiência dinâmica ${ }^{12}$, pois "seu ritmo de desenvolvimento não foi capaz de responder às exigências peremptórias da expansão demográfica e é enorme o potencial humano que se desperdiça de uma ou outra forma, em detrimento da economia, da equidade distributiva e da convivência social" (PREBISCH, 1973, p. 3). De acordo com o mecanismo de análise de insuficiência dinâmica, o protagonismo da indústria e das atividades conexas justificam o fenômeno da urbanização descontrolada. De modo geral, Prebisch expõe que os setores mencionados tendiam a crescer mais rápido que o nível da renda, atraindo assim desempregados e a população do campo que buscavam maiores rendimentos, com isso, cabia à indústria o papel de absorver essa mão de obra excedente. Sob a hipótese de a indústria cumprir a sua função de

\footnotetext{
${ }^{9}$ A terra se encontrava na mão de poucos e, por consequência, não garantia o seu uso de forma eficiente. $\mathrm{O}$ resultado era a ampliação do excedente da mão de obra e subemprego, desencadeando um processo de urbanização desenfreado (PREBISCH, 1968).

${ }^{10}$ Ainda nos anos de 1950, Prebisch já tratava da incapacidade em absorver força de trabalho presente na periferia. Para o autor, esse fenômeno se relacionava à estrutura da região com pouca aptidão para formar capital e pelo consumo das classes ricas desconectado do investimento (PREBISCH, 2011). Todavia, esse tema retomou em Prebisch sob uma nova perspectiva, englobando problemas de uma estrutura latifundiária que entorpece o desenvolvimento.

${ }^{11}$ Suficiência dinâmica também era um conceito operacional para mensurar o dinamismo econômico. Em Desenvolvimento e Transformação (1973), Prebisch utiliza esse conceito para realizar projeções com intuito de determinar o esforço que uma economia necessita fazer para alcançar o nível de absorção necessário para controlar o processo de urbanização em um determinado período.

${ }^{12}$ Como aponta Gurrieri (2011), é importante esclarecer o conceito de "insuficiência dinâmica", pois pode levar erroneamente a compreensão de que indica algum tipo de estagnação econômica, como tratado na seção seguinte em Furtado. $\mathrm{O}$ conceito se refere à capacidade de absorção da economia, sendo assim, pode indicar um baixo dinamismo da economia, não mais do que isso.
} 
absorção, a produtividade do setor agrícola seria ampliada com a absorção da sua ociosidade pela indústria. Ainda nesse raciocínio, os ganhos com progresso técnico de uma economia resultariam em ganhos de produtividade, que em contrapartida exigiriam novos investimentos e, em paralelo, uma taxa mínima de aumento da renda para o seguimento do processo de acumulação. Cumprindo-se tais exigências, a ampliação da dinâmica da economia e o impulso para um novo ciclo seriam o resultado deste mecanismo (PREBISCH, 1968). A figura 1 ilustra o diagnóstico da crise de Insuficiência dinâmica.

Figura 1 - Diagnóstico da crise de insuficiência dinâmica

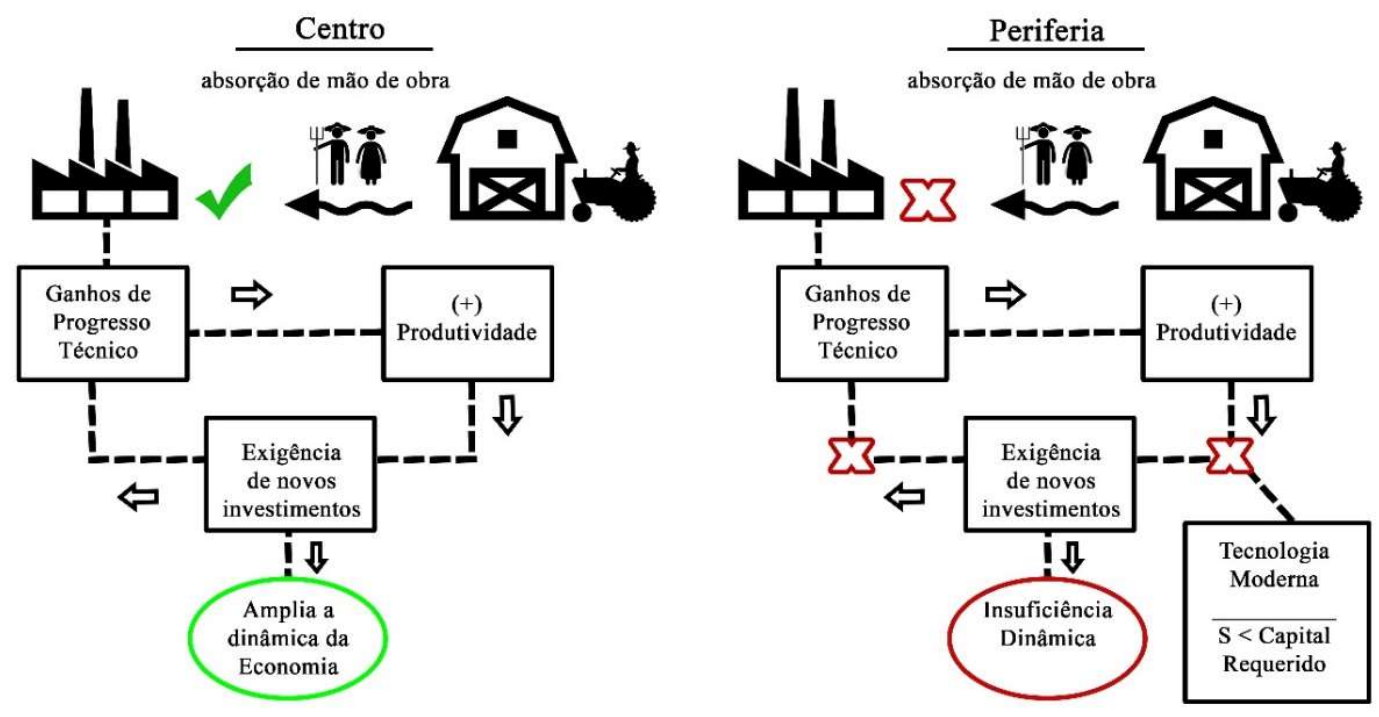

Fonte: Elaboração própria a partir de Prebisch (1968, p. 33).

Como exposto na figura, na interpretação de Prebisch, na América Latina, ainda mais pressões demográficas seriam lançadas ao setor industrial devido a estruturas do campo concentradas e arcaicas. Haveria também um descompasso na exigência por certo nível de investimento, uma vez que o capital requerido na periferia, via de regra, seria superior à poupança da região, que já apresentava um nível baixo, em contraste ao seu desvio pelas classes altas para satisfazer padrões de consumo supérfluos. Ainda que fosse o único problema, Prebisch acrescenta o fato de a periferia não controlar o progresso técnico ${ }^{13}$, o que causava complicações ao utilizar uma tecnologia planejada para um nível de desenvolvimento distinto do seu.

\footnotetext{
${ }^{13}$ Isto é, a periferia não obtém domínio de um sistema de inovação, a tecnologia utilizada é assimilada dos grandes centros econômicos (PREBISCH, 1968).
} 
As contradições a respeito da propagação do progresso técnico foi outro ponto abordado como empecilho para a dinâmica econômica. Conforme Prebisch (1968), os países latino-americanos careciam de medidas para elevar sua produtividade e, por resultado, imobilizavam sua capacidade de absorção de mão de obra. A discrepância desse problema reside na assimilação da técnica moderna, cuja sua elaboração seria efetuada em grandes centros e preparada para poupar mão de obra, alargando o volume demandado de capital. Diferente do centro, que possuía capital em excesso e mão de obra limitada, a estrutura da periferia carecia de aptidão para formar capital, e em contrapartida exibia um excesso de oferta de trabalho, o que conduzia a região a um dilema no qual assimilar novas técnicas ampliava ainda mais o desemprego e a má distribuição da renda, agravando, assim, a insuficiência dinâmica.

Apesar dessa contradição, deixar de absorver técnicas modernas seria um retrocesso para os países latino-americanos, mesmo com o constante agravamento do problema da insuficiência. Prebisch (1968) deixa claro que não haveria soluções espontâneas, e que o problema seria de difícil solução, pois os empresários não levavam em consideração o emprego da mão de obra em seu cálculo econômico; pelo contrário, consideravam apenas a redução imediata dos custos. Uma possível solução estaria em encontrar uma relação entre o custo do trabalho e do capital que, simultaneamente, assegurasse o emprego ótimo ${ }^{14}$ de mão de obra. Em outras palavras, seria buscar uma combinação que permitisse a maior absorção compatível com o incremento máximo do produto, o que exigia atuação por parte do Estado no processo de propagação das técnicas.

Nesse aspecto, ao fenômeno da deterioração dos termos de troca, que foi plano de fundo da formulação teórica de Prebisch desde seu primeiro escrito na CEPAL, acrescentava-se um determinante também interno. Anteriormente, o conceito se referia à perda dos produtos primários no comércio internacional diante dos produtos manufaturados devido a sua elasticidade-renda da demanda. A partir de então, a incapacidade da indústria em absorver mão de obra do campo também influenciaria a queda do nível de preço dos produtos primários, sendo que os

\footnotetext{
${ }^{14}$ Ao tratar da questão emprego ótimo, é pertinente ter em mente que o autor também estava considerando a qualidade do emprego. Segundo Hodara (1987), além de Prebisch ter tratado da questão do emprego informal que aparece no setor urbano oferecendo uma precária condição para a força de trabalho, o autor também fez uso do conceito de "redundância", sendo este também um indicador da insuficiência dinâmica. O trabalho redundante, para Prebisch, estava associado ao trabalho que mesmo quando desaparece, não reduz a produção.
} 
ganhos de produtividade do campo ao invés de transmitidos aos salários seriam convertidos em lucros elevados aos proprietários que, por sua vez, expandiriam a produção para além do ritmo da procura, provocando a queda do nível de preços dos produtos primários (PREBISCH, 1968).

O modelo desenvolvimento hacia adentro vigente também foi alvo de críticas do autor. Afinal, o desenvolvimento baseado em exportar bens primários apoiando uma ISI encontrava seu esgotamento nos países que mais avançaram no processo de industrialização. $\mathrm{O}$ excesso de protecionismo praticado na América Latina constituiu uma indústria isolada do resto do mundo com custos elevados e sem qualquer critério econômico, onde prevaleciam apenas diretrizes imediatistas. Conforme Prebisch (1973, p. 196), formou-se uma

\begin{abstract}
industrialização ineficiente e cara, pela consabida estreiteza dos mercados e o fraco incentivo da concorrência, leva dentro de si mesma o germe de sua própria debilitação dinâmica, pois se desenvolve num regime autônomo de custos e preços que - por não ter contato com mercado internacional - desestimula as exportações de produtos industriais, que são verdadeiramente indispensáveis, uma vez que a indústria precisa voltar-se para fora do país a fim de se desenvolver internamente em profundidade.
\end{abstract}

A cooperação internacional ${ }^{15}$ seria a opção escolhida por Prebisch para atenuar tais problemas e obter uma melhor articulação no mercado mundial ${ }^{16}$. Na visão do autor, uma política de cooperação deveria envolver a combinação de esforços internos e externos, fragmentando-se em uma cooperação no âmbito financeiro e comercial (PREBISCH, 1973). Primeiramente, a cooperação financeira estaria vinculada à resolução das dificuldades do âmbito interno entre as economias latino-americanas, assim evitando um esforço individual de acumulação profundo e prolongado. Essa cooperação teria por base a complementação da poupança interna, podendo reduzir a dependência do capital estrangeiro a fim de manter a reciprocidade entre os países e reduzir o poder dos credores. O repasse de recurso deveria, impreterivelmente, ser realizado por

\footnotetext{
${ }^{15}$ Prebisch já vinha trabalhando desde a segunda metade da década de 1950 neste tema dentro da CEPAL, formalizando uma estratégia de desenvolvimento para criação de um Mercado Comum Latino-americano (GONÇALVES, 2011).

${ }^{16}$ Conforme Couto (2017), a proposta de cooperação internacional descrita por Prebisch, em sua obra do ano de 1970, é um reflexo das discussões empreendidas pelo autor na direção das conferências da UNCTAD em Genebra no ano de 1964 e Nova Dehli no ano de 1968.
} 
instituições multilaterais guiadas com base nos princípios do multilateralismo financeiro (PREBISCH, 2011a).

No caso dos persistentes problemas de estrangulamento externo, o combate seria efetuado por uma cooperação comercial. A base da proposta de cooperação estaria no incentivo à exportação de manufaturas. O centro capitalista mostrava-se fechado para importar manufaturas da periferia, assim o esforço de industrialização voltava-se para o mercado interno, por consequência, alcançando pontos de estrangulamento. Nesse panorama, caberia aos países latino-americanos expandirem seus respectivos comércios com base na própria região, uma vez que, apesar da proximidade, o intercâmbio comercial entre eles ainda era muito limitado a poucos produtos primários. De acordo com Prebisch (2011c), essa postura deveria ser alterada e a regionalização da ISI $^{17}$ seria o caminho indicado para dar continuidade em um projeto de industrialização planejado.

Com respeito às inflexibilidades estruturais internas, Prebisch apontava para a necessidade de introdução de mudanças que seriam pré-requisitos essenciais - as reformas de base e estruturais. Fatores como expansão de mercados, definir tecnologia, ampliar a capacidade de poupança mostravam-se ingredientes fundamentais para modernização da estrutura econômica, ainda que insuficientes. Reformas estruturais do sistema político e social sob a atuação deliberada do Estado representariam precondições para evitar o fracasso do projeto de desenvolvimento (PREBISCH, 1973). Nesse caso, o receituário para a crise de Prebisch expunha algumas medidas que deveriam estar na agenda das economias da América Latina.

A péssima distribuição da renda criou na América Latina uma classe com padrão de renda elevada que desfrutava dos benefícios oferecidos pela tecnologia moderna, alimentando a demanda de indústrias com menor absorção de mão de obra. Como parte considerável do consumo dessa classe advinha de privilégios da sua posição dominante, o progresso técnico se tornava refém dessa estrutura de renda que inibia qualquer incentivo ao desenvolvimento. Em função disso, Prebisch (1973) levantava a necessidade de compreensão do consumo desses grupos minoritários em conjunto da utilização de progressivas medidas de

17 A regionalização da ISI deveria garantir ao setor industrial obter ganhos de escala externos e especialização produtiva industrial entre as economias da região. Por resultado, ampliando a capacidade de sobrevivência da indústria da América Latina (PREBISCH, 2011a). 
redistribuição de renda, cujo intuito seria estender um esforço maior de formação de capital.

Outro fator debilitante do desenvolvimento estaria na estrutura agrária latino-americana, visto que esta atuava como um obstáculo estrutural privando a mobilidade social e enfraquecendo o progresso técnico. As causas desse problema vinculavam-se à forma arcaica do regime de posses moldado pela monopolização da terra em poucas mãos e à proliferação de minifúndios. Em contrapartida, a oferta abundante de mão de obra auxiliava ainda mais a apropriação dos frutos do progresso técnico pelos grandes proprietários de terra. $\mathrm{Na}$ compreensão de Prebisch (1973, p. 195),

enquanto não se transforme a estrutura agrária, a fim de dar terra ao camponês que não a tem e aumentar a superfície do que a tem, na medida em que torne possível a pressão demográfica. Desta forma, poderá aquele participar de modo mais equitativo das vantagens do progresso técnico [...]. Sem isso, a disparidade social continuaria se acentuando.

Com efeito, a solução da crise para Prebisch expressa em suas obras estaria além de programas meramente redistributivos, sendo necessário promover modificações radicais na estrutura da região, como a reforma agrária. O próprio Prebisch (1982) alega que, na fase em que esteve na UNCTAD, obteve uma compreensão melhor do funcionamento do sistema, tanto no centro quanto na periferia, cristalizados em seus escritos a partir de 1976, já fora daquele órgão internacional. A afirmação de Prebisch sobre a compreensão do sistema diz respeito às críticas ao capitalismo com que iniciou em sua obra Transformação e Desenvolvimento (1973). De acordo com o autor, um sistema que não corrigisse o problema da insuficiência dinâmica muito menos fosse capaz de distribuir equitativamente a renda não apresentaria motivos para seu prolongamento.

Dentre os temas abordados por Prebisch, a questão do crescimento populacional também era considerada ${ }^{18}$, uma vez que o extraordinário crescimento demográfico exigia um ritmo de desenvolvimento cada vez maior para região. Para o autor, os avanços científicos e tecnológicos que a região experimentou fizeram-

\footnotetext{
18 Prebisch, em sua obra Dinâmica do Desenvolvimento Latino-Americano (1968), evita discutir o crescimento populacional, apesar de reconhecê-lo como um grave entrave, o autor considera o assunto delicado, sendo capaz de ferir os sentimentos dos latino-americanos. Entretanto, em uma de suas obras posteriores $_{2}$ Transformação e Desenvolvimento (1973), aponta a necessidade de discussão do tema.
} 
na reduzir significativamente a taxa de mortalidade; paralelamente, não houve modificações comportamentais no que tange à atitude das famílias com respeito à taxa de natalidade. Nesse contexto, o receituário de Prebisch levantava a necessidade de políticas familiares com base essencial no papel da educação. $O$ autor ressalta que a taxa de natalidade da região desceria espontaneamente ao avanço do desenvolvimento, com a melhora de alguns hábitos sociais. Porém, adverte que o quanto antes fossem difundidos esses hábitos e implementadas as medidas de controle de natalidade, mais depressa se poderia corrigir tal distúrbio que pressionava a suficiência dinâmica da América Latina (PREBISCH, 1973).

O conjunto de medidas apontadas por Prebisch se apoiava na eficácia do planejamento econômico. De acordo com o autor, haveria uma crise de planejamento na América Latina, que representava "alguma coisa a mais do que a crise de um método ou de uma técnica, pois os obstáculos que se opõem ao planejamento são os mesmos que dificultam o avanço da concepção estratégica do desenvolvimento" (PREBISCH, 1973, p. 219). A problemática não estaria apenas sob os responsáveis pelo planejamento, sendo que o próprio conceito de planejar, ou interferir, sofria resistência na América Latina. Em todos os países da região, a ação do Estado foi admitida para preservação da ordem existente, mas quando se tratava de modificá-la, revelavam-se incontáveis barreiras.

Em síntese, o chamado por Pedrão (2011) de "capitalismo progressista de Prebisch" seria, fundamentalmente, uma alternativa reformista que almejou a resolução dos problemas internos da estrutura social da região, mas também um freio aos interesses do centro, buscando uma reforma equitativa no comércio internacional. Tudo isso sem alterar a validade da sua análise inicial sobre a tendência ao estrangulamento externo. Com respeito à crise da época, Prebisch salienta que uma

grande tarefa que se tem pela frente. É de grande importância a estrutura do poder; e também possuem importância em alto grau as ideias que guiam a quem dela participa, a convicção de que é possível, com grande esforço, superar esta crise e dar um forte impulso ao desenvolvimento, sem continuar a sacrificar a equidade distributiva, nem comprometer o próprio sentido da coesão nacional. Não contando com isso, o desenvolvimento não poderia assentar-se em bases firmes e duradouras (PREBISCH, 1973, p. 224). 


\section{Celso Furtado e a Tendência Inexorável à Estagnação}

O diagnóstico da crise dos anos de 1960, em Celso Furtado, apontava que o avanço do processo de industrialização periférica estaria encontrando o seu limite em consequência de fatores estruturais. Em outras palavras, o autor defende a tese de uma tendência inexorável à estagnação nas economias latino-americanas. Diferente de Raúl Prebisch, com seu diagnóstico de insuficiência dinâmica visto anteriormente, Furtado assume uma perspectiva de maior desilusão, o que Bielschowsky (2011b) identifica como um tom mais pessimista e efêmero em sua reflexão da crise.

$\mathrm{O}$ argumento de Furtado tem sua construção em Dialética do Subdesenvolvimento $(1964)^{19}$, no qual reúne diversos ensaios em que discute a essência do problema do subdesenvolvimento e as causas da crise que atravessava a região. Já em Subdesenvolvimento e Estagnação na América Latina (1968), Furtado reafirma suas conclusões formalizando em um modelo teórico o problema do crescimento econômico da região. Ao longo desse período, Furtado, diferentemente de Prebisch, não mantinha mais seu vínculo com a CEPAL, pois a queda do regime democrático no Brasil com o golpe de 1964 o impôs o exílio, que o levou a se dedicar a carreira acadêmica no exterior ${ }^{20}$.

A base metodológica de Furtado, na década de 1960, tem início no resgate da tradição do pensamento marxista ${ }^{21}$ de um modelo dinâmico de representação da realidade social, a dialética. Marx, ao identificar as forças primárias que provocam reações sob a forma que o processo de desenvolvimento histórico é apresentado, dirige sua atenção às relações de produção e à estrutura social. Como pontua Furtado (1964, p. 19), a partir da proposta de Marx, "toda vez que em determinadas condições históricas avança a tecnologia e se desenvolve as bases materiais, todos os demais elementos serão chamados a ajustar-se". Nesse sentido, o autor conclui que as alterações na estrutura social - superestrutura - estão condicionadas a modificações na estrutura econômica - infraestrutura.

\footnotetext{
19 Dentro da obra Desenvolvimento e Subdesenvolvimento (2009) já se encontra de forma mais branda discussões sobre a distribuição de renda como entrave ao desenvolvimento, Bielschowsky (2011a) alega que Furtado foi o primeiro a tratar do problema da distribuição de renda dentre os estruturalistas.

${ }^{20}$ Sobre a trajetória intelectual de Celso Furtado, ver Guimarães (2001).

${ }^{21}$ Furtado (1989) argumenta que ao colocar a análise das estruturas sociais e econômicas como forma de compreender o comportamento dos agentes, os estruturalistas têm influência teórica de cunho marxista.
} 
Partindo dessa compreensão, Furtado (1964, p. 23) percebe a incapacidade da análise econômica moderna em "captar os fenômenos econômicos em desenvolvimento, como aspecto de um processo mais amplo de mudança social". Desse modo, atividades e hábitos - inovações - absorvidas de outras culturas provocam reações que repercutem em toda esfera social. Portanto, o desenvolvimento econômico deve ser compreendido também como um processo de mudança social, no qual as necessidades humanas são satisfeitas através de alterações no sistema produtivo decorrente de inovações tecnológicas.

Tendo em vista que as inovações tecnológicas provocam um acréscimo no excedente econômico, podendo ser utilizado para ampliar a capacidade produtiva ou na melhoria imediata do bem-estar social, o próprio mecanismo de apropriação do excedente deriva em um conflito social, ou como intitulado por Marx, resulta na luta de classes. Conforme Furtado (1964), tal conflito não causa o entorpecimento do desenvolvimento econômico, muito pelo contrário, ele atua como motor do capitalismo. Pressões por parte dos trabalhadores em busca de ampliar sua participação nos frutos do desenvolvimento não comprometem o desempenho do capitalista sob pena de redução da sua poupança, uma vez que a classe capitalista é capaz de contra-atacar com o uso de inovações tecnológicas capazes de compensar a margem do aumento dos salários; assim, o próprio conflito de classes resulta em impulsos no avanço do progresso técnico. Os países do centro não demoraram a notar os benefícios desse conflito, permitindo que esse processo fosse institucionalizado com a utilização de sindicatos e demais mecanismos ${ }^{22}$. Em função disso, pressões por salários maiores em conjunto da demanda por menor carga horária de trabalho por parte da classe trabalhadora exigiam um aperfeiçoamento do processo de inovação. Ao se referir aos benefícios da luta de classes, Furtado alude a uma redução da mais-valia relativa, resultado que ao reduzir a quantidade de trabalho necessária atingiria a classe trabalhadora com a redução da jornada de trabalho, ao invés de ser apropriado totalmente pelo capitalista.

Ter o comando do progresso técnico é um conceito chave para interpretação de Furtado. Pelo fato de as economias subdesenvolvidas absorverem tecnologia de grandes centros, sua adaptação torna-se de imediato um problema de maior

\footnotetext{
${ }^{22}$ Conforme Carmo Sobrinho (2001), Furtado tinha como referência o capitalismo europeu no período social-democrata ao tratar dessas questões.
} 
complexidade, pois o processo de industrialização periférico aconteceu de forma tardia e sem a eliminação do setor pré-existente ${ }^{23}$. Tal estrutura dual, quando entra em contato com as tecnologias modernas, termina por agravar ainda mais o dualismo entre as estruturas econômicas, uma vez que a composição da tecnologia utiliza o mecanismo de poupar mão de obra, criando um entrave no processo de absorção da força de trabalho e produzindo subemprego.

Por consequência, o fato de a periferia não ter o comando do seu progresso técnico impede-a de utilizar uma tecnologia apropriável ao seu estilo de desenvolvimento - conclusão análoga a apresentada em Prebisch (1963). Essa situação também refletiria na dificuldade em solucionar o conflito de classes, pois pressões por crescentes salários terminam sendo resolvidas no campo político, por conseguinte, perdendo um dos fatores essenciais do dinamismo capitalista. Tais contradições da estrutura periférica levam Furtado a um diagnóstico reformista ao deslocar o problema para a estrutura interna. Para o autor, sendo o desenvolvimento econômico "fundamentalmente um processo de incorporação e propagação de novas técnicas, implica em modificações de tipo estrutural, tanto no sistema de produção como no de distribuição" (FURTADO, 1964, p. 61).

Diante dessa exposição teórica, na percepção de Furtado, a causa da crise seria estrutural, e estaria relacionada a formas anacrônicas de distribuição de renda presentes na América Latina. A estrutura social concentrada se traduzia em insuficiência na demanda final para o consumo e investimento, distorcendo a utilização do produto social - o excedente -, sendo condição necessária do processo de acumulação de capital. Segundo Furtado (1964, p. 62),

\begin{abstract}
não apenas da acumulação depende o desenvolvimento. Apoia-se este, igualmente, na força dinâmica que surge nas sociedades sob a forma de impulso para a melhoria das condições de vida. Se o incremento do produto, decorrente da acumulação, permanecesse indefinidamente concentrado nas mãos dos pequenos grupos dirigentes, o processo de formação de capital tenderia a um ponto de saturação. É porque parte apreciável desse novo produto se distribui entre as massas trabalhadoras, que o desenvolvimento pode-se seguir adiante.
\end{abstract}

\footnotetext{
${ }^{23}$ A estrutura periférica sofre com o fenômeno da heterogeneidade estrutural, sendo que uma estrutura moderna convive com estruturas anacrônicas, ou pré-capitalistas. Em razão disso, a estrutura permanece com a mão de obra ilimitada, tornando a oferta de mão de obra elástica, consequentemente, dificultando a transferência dos ganhos de produtividade para os níveis de salário (FURTADO, 1968).
} 
Em síntese, na década de 1960 Furtado via na permanência do subdesenvolvimento um problema em termos da estrutura social e seus reflexos na propagação do progresso técnico. Tal estrutura seria a raiz de uma tendência à estagnação que caracterizava as economias em condições periféricas. Em Dialética do Subdesenvolvimento (1964), o autor se preocupou com a origem do reduzido dinamismo interno, sem se dirigir, entretanto, diretamente ao problema do crescimento das economias subdesenvolvidas, o que faria em Subdesenvolvimento e Estagnação na América Latina (1968).

Como exposto por Furtado, ao longo dos anos de 1960 "a experiência tem demonstrado na América Latina, que esse tipo de industrialização substitutiva tende a perder impulso quando se esgota a fase das substituições 'fáceis', e eventualmente provoca estagnação" (FURTADO, 1968, p. 39). Em busca de compreender o alcance do processo de industrialização na América Latina, Furtado analisou o problema do crescimento na fase "difícil"24 do processo de industrialização. O exame de Furtado teve como ponto de partida a nova composição da técnica empregada pelos novos setores. Primeiramente, o setor de bens de consumo duráveis apresentava um elevado coeficiente de capital, que, por seu turno, determinou um volume de investimentos necessários cada vez maior para o emprego de um número igual de trabalhadores, isto é, esse setor poupava mão de obra. No caso do setor de bens de capital, as dimensões de mercado prevalecentes na América Latina não comportavam suas exigências, assim forçavam as empresas a atuarem sob capacidade ociosa, consequentemente, com custos crescentes. Além do mais, havia o problema da debilidade e inadequação do setor financeiro na América Latina, sendo baixa a capacidade no financiamento de longo prazo nas empresas. Nessa perspectiva, tais setores apenas poderiam desenvolver-se com base em níveis elevados de preços relativos e elevado grau de proteção contra concorrência internacional (FURTADO, 1968).

\footnotetext{
${ }^{24}$ Convencionalmente a literatura classifica a ISI por dois momentos. A primeira, intitulada fase "fácil", refere-se ao início do processo substitutivo, quando um determinado país inicia a instalação de indústrias de bens de consumo não-duráveis, indústria têxtil. A fase posterior, classificada por “difícil”, está associada à instalação das indústrias subsequentes, passando por indústrias pesadas como metalúrgicas, até as indústrias de bens de consumo duráveis e bens de capital, chamadas no período por indústrias modernas.
} 
A ênfase no fenômeno da estagnação descrito por Furtado se encontra na evolução decrescente da relação produto-capital ${ }^{25}$ com a predominância da indústria moderna. O prelúdio do esquema teórico de Furtado está em contradições do sistema tecnológico com técnicas cada vez mais intensivas em capital, reduzindo a absorção de mão de obra, promovendo a concentração funcional da renda e uma estrutura de demanda altamente concentrada. A figura abaixo busca sintetizar o processo de estagnação descrito por Furtado.

Figura 2 - Tese de tendência à estagnação de Celso Furtado

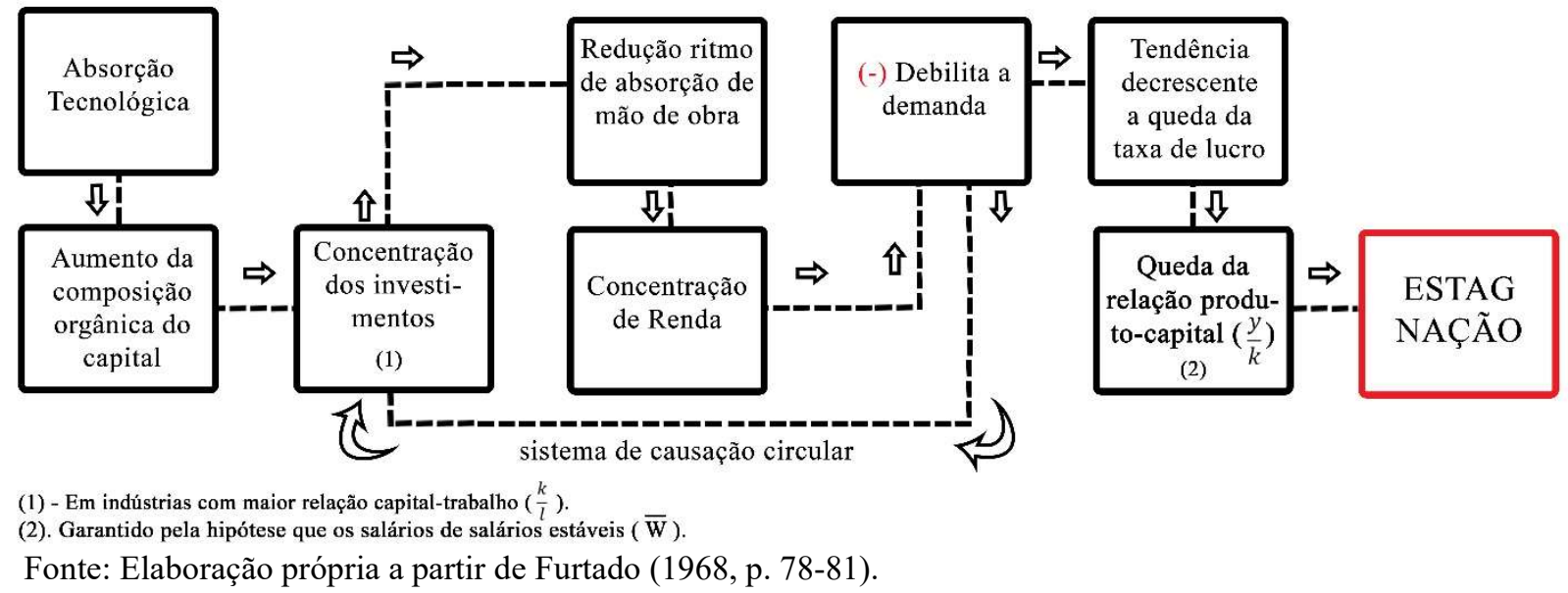

Como exposto na figura 2, a concentração de renda estava sendo determinada e realimentada pelo próprio mecanismo de desenvolvimento estabelecido na América Latina, visto que o elevado coeficiente de capital causava uma nova concentração de renda ${ }^{26}$, reduzindo progressivamente a participação das massas salariais com relação ao produto, e, assim, desencadeando um processo de causação circular. Supondo salários estáveis ${ }^{27}$, o resultado seria a redução da taxa de crescimento com o declínio da relação produto-capital. Em síntese:

À medida que a industrialização prosseguia na direção de estágios mais
avançados, os novos setores não só eram cada vez mais intensivos em
capital, como exigiriam cada vez maiores escalas. [...] O resultado seria
uma tendência simultânea à queda na taxa de lucro, à redução na
participação dos salários na renda e à falta de mercado consumidor para

${ }^{25}$ A relação produto-capital indica que o acréscimo de produção é determinado pelo acréscimo de capital, com o declínio de tal relação impõe-se contradições na taxa de lucro com efeitos negativos na poupança (FURTADO, 1968).

${ }^{26}$ Sob a hipótese de que os investimentos se concentravam nas indústrias com maior relação capitaltrabalho.

${ }^{27}$ Assumindo a hipótese de que os salários são determinados por fatores exógenos ao mercado na periferia, Furtado considera o salário como uma variável estável (FURTADO, 1968). 
os novos produtos, com consequente perda de dinamismo e tendência à estagnação (BIESCHOWSKY, 2000a, p. 72).

A tese de estagnação de Furtado extrapola uma teoria do crescimento econômico devido a sua ligação com a estrutura social. Furtado (1968) levanta dois fatores que agravavam o processo de distribuição de renda na América Latina. $\mathrm{O}$ primeiro referia-se a uma pequena parcela da população que mantinha e tinha como objetivo manter padrões de consumo mimetizados de classes de renda elevada dos centros capitalistas. Essa parcela da população estaria modificando a composição da demanda e determinando uma estrutura produtiva industrial com baixo padrão empregador, o que reforçava o efeito concentrador de renda. No segundo grupo estariam as indústrias transnacionais que atenuavam a atuação do Estado nas decisões do planejamento econômico. Isso se evidenciaria pelos equipamentos adquiridos pelas empresas de suas matrizes no exterior, os quais não comportavam a necessidade de uma estrutura periférica. Ao invés de poupar matéria prima, ou até mesmo simplificar os processos produtivos, as transnacionais selecionavam, assim, tecnologias com elevado coeficiente de capital.

Verificava-se, desse modo, que a natureza do problema seria de caráter essencialmente estrutural. A industrialização não promoveu o desenvolvimento, pelo contrário, apenas a modernização para um tipo de economia em que os ganhos com o aumento da renda eram absorvidos por uma pequena minoria. Tal parcela da população beneficiava-se de um padrão diferenciado, sem qualquer preocupação com um plano mais amplo de desenvolvimento nacional. Assim, a má distribuição da renda tornava-se o traço essencial da nova estrutura condenada à estagnação.

Diante de tais conclusões, o receituário de Furtado para o novo panorama do desenvolvimento da América Latina não residiria em uma proposta de domínio puramente econômico, mas envolveria questões políticas, sociais e alterações em todo marco institucional. Para Furtado (1968), reformas pesadas na estrutura da terra - reforma agrária - e medidas efetivas de distribuição de renda deveriam ser viabilizadas, retomando e ampliando o papel do Estado no que tange ao planejamento econômico como ferramenta efetiva para enfrentar as mazelas do subdesenvolvimento. Superar tal crise, na percepção de Furtado, seria modificar toda estrutura econômica e social, supondo um tipo de revolução social planejada 
que envolveria o engajamento de toda população em um projeto nacionalista, cuja finalidade principal seria a superação do subdesenvolvimento.

Como afirma Bielschowsky (2000a), a formação das economias periféricas deixou uma estrutura da terra sob controle de uma pequena minoria representada por latifundiários rentistas que distorciam o uso do excedente econômico. Assim, a defesa da necessidade de uma reforma agrária, em Furtado, visava modificar toda estrutura concentrada da riqueza, cuja raiz remontava à economia colonial escravocrata. Os benefícios conquistados com a reforma trariam proveitos com a geração de uma poupança potencial disponível para fins de investimento produtivo e ampliação do mercado interno, fornecendo acesso à terra ao camponês.

O marco político representava outra importante reforma. Para Furtado (1968), a formulação de uma política de desenvolvimento para a América Latina estaria atrelada à capacidade dos líderes de mobilizarem as massas populares. Um projeto nacionalista era o propósito do autor, em que o desenvolvimento seria conduzido por centros políticos nacionais com base nos valores e ideias de cada nacionalidade. A preocupação de Furtado com a situação política da região estava vinculada a sua experiência como ministro do Planejamento no Brasil. Em 1963, Furtado implementou o Plano Trienal ${ }^{28}$, que tinha como objetivos restabelecer a situação econômica do país e implementar medidas de justiça social, como a reforma agrária, isto é, utilizar um receituário reformista como saída da crise que o país enfrentava (BIELSCHOWSKY, 2000). Com a queda do regime democrático em 1964, as diretrizes políticas do regime militar substituíram o enfoque reformista de Furtado, tendo no Plano de Ação Econômica do Governo (PAEG) uma reforma salarial como principal medida anti-inflacionária, e que atuava deteriorando o salário real da grande massa da população ${ }^{29}$.

Tendo tratado da problemática do subdesenvolvimento, o receituário de Celso Furtado dos anos de 1960 afirmava que apenas com uma ampla participação social com forte apoio político, junto com a realização de importantes reformas estruturais e institucionais, poderia ser contornado a crise de caráter essencialmente estrutural. Como consequência, haveria uma ampliação do consumo na direção dos produtos industriais com menor coeficiente de capital,

\footnotetext{
${ }^{28}$ O Plano Trienal foi abandonado alguns meses após o anúncio devido à crise política (BIELSCHOWSKY, 2000).

${ }^{29}$ Para mais informações com respeito as medidas utilizadas no PAEG, ver Resende (2014).
} 
contribuindo para retomar o dinamismo com a recomposição dos investimentos industriais, isto é, a retomada de um projeto de desenvolvimento de forma não excludente e democrática.

\section{Considerações finais}

A preocupação fundamental e objetiva de Raúl Prebisch e Celso Furtado esteve sempre dirigida para a superação do subdesenvolvimento da América Latina. Na década de 1960, uma crise desarticulou o pensamento desenvolvimentista que, até então, assegurava uma certa identidade entre industrialização e desenvolvimento. O ponto de partida deste artigo foi pensar tal crise a partir de sua dimensão teórica, bem como uma crise do pensamento desenvolvimentista - como cunhado por Bielschowsky (2000).

Diante da crise, os autores deslocaram a discussão sobre o desenvolvimentismo para um quadro conceitual reformista. A exposição elaborada por Furtado e Prebisch reconhecia que o atraso do desenvolvimento periférico não se devia somente a forças externas, o funcionamento da dinâmica interna também deveria ser estudado. Para tal, ambos os autores mobilizaram conceitos com o intuito de estabelecer uma linha argumentativa que estabelece relação entre padrões de distribuição de renda e o modo de acumulação de capital.

Nesse sentido, Prebisch demonstrou vitalidade e capacidade de atualização de seu pensamento. Com ênfase no desemprego estrutural e utilizando o conceito de insuficiência dinâmica, apontou a incapacidade das estruturas econômicas da América Latina em incorporar sua força de trabalho. Pedrão (2011) alega que a causa desse malefício, para Prebisch, não era necessariamente a falta de capital, a raiz do problema estava, fundamentalmente, numa estrutura social concentrada que entorpecia a mobilidade social e na composição da tecnologia moderna poupadora de mão de obra. Furtado, por sua vez, vislumbrou a impossibilidade do avanço da ISI em sua fase avançada. Padrões distributivos concentradores alimentados pela indústria moderna determinavam uma tendência inexorável à estagnação. Furtado representava esse fenômeno por meio da queda da relação produto-capital à medida que era incrementado o coeficiente de capital por unidade de trabalho com o uso da técnica moderna. 
Quanto ao receituário de ambos os autores, havia uma convergência pelo tema das reformas. O Estado deveria promover reformas de base e alterar todo o marco institucional da região. A reforma agrária assim como medidas distributivas estavam no cerne de uma proposta de ação apoiada no eixo crescimentodistribuição. As semelhanças entre os autores não estavam restritas a isso. Segundo Bielschowsky (2011), Furtado e Prebisch fazem uso da mesma estratégia argumentativa de contrastar a periferia com o centro com o intuito de fortalecer a noção de que a estrutura latino-americana, ao contrário do centro, permaneceu com sua heterogeneidade estrutural. Consequentemente, isso refletiu em contradições na estrutura produtiva e distributiva, impedindo a transmissão da produtividade para o rendimento dos trabalhadores.

Outro ponto fundamental é o caráter multidisciplinar que começa a aflorar na produção teórica de Furtado e Prebisch. Entretanto, ao passo que Furtado buscou na tradição marxista um modelo para interpretar a estrutura social da região. Couto (2017) afirma que Prebisch, em contraste, englobou posições sociológicas acerca da estrutura social, preocupando-se com o estudo da distribuição dos frutos do progresso técnico dentro da estrutura interna da América Latina. Há também divergências fundamentais dentro dos esquemas teóricos de Furtado e Prebisch. O próprio argumento em favor da reforma agrária aparecia de forma distinta. Em Prebisch, tal reforma não auxiliava a industrialização com o incremento do mercado interno, como apresentou Furtado. De acordo com Bielschowsky (2000a), a ênfase de Prebisch recaiu na necessidade de investimento produtivo para absorção de mão de obra. Furtado, por seu turno, concentrou-se na ótica da demanda. O mesmo pode ser pensando quando se trata da absorção da tecnologia e suas contradições. Por mais que Furtado e Prebisch tivessem visto o problema da técnica moderna de forma semelhante - não sendo ela adequada para a estrutura periférica -, novamente, aqui, Furtado enfatizou que os efeitos do aumento do coeficiente de capital recaíram sobre a demanda. Prebisch, por outro lado, apontou os efeitos sobre a insuficiência dinâmica, isto é, o emprego.

Outra diferença marcante encontra-se na interpretação no bloqueio estrutural da ISI presente na América Latina. Ao tratar do tema, Furtado mostrouse mais cético, afirmando que o bloqueio representou um processo de estagnação em curso. Para Prebisch, esse fenômeno debilitou a dinâmica da economia, consequentemente, exigindo um esforço cada vez maior de investimento produtivo 
ampliando a distância entre os países desenvolvidos e subdesenvolvidos. Portanto, Prebisch não falava em estagnação. O maior grau de radicalismo teórico presente em Furtado pode ser explicado dentro da posição ocupada por ambos os autores ao longo da década de 1960. Como expõe Hodara (1987), a intenção das obras de Prebisch apresentadas aqui sobrepunha questões acadêmicas. Tais obras também eram críticas veladas à atuação dos governos no processo substitutivo, bem como ao excesso de proteção praticado na ISI, à defesa de interesses de elites regionais, entre outros. Além disso, a própria posição de diretor de organismos institucionais colocou chefes de governos como "clientes" de Prebisch, assim tendo que produzir uma argumentação, de certa forma, neutra acerca dos problemas do desenvolvimento. O mesmo não aconteceu com Furtado, que estava exilado do Brasil dedicando-se à carreira acadêmica no exterior, não mais como um técnico de algum membro de algum órgão internacional.

Em suma, a crise do pensamento desenvolvimentista na década de 1960 trouxe para Furtado e Prebisch novos problemas que exigiram o aperfeiçoamento do seu instrumental analítico. Em vista disso, ambos os autores tomaram consciência da função da estrutura interna da América Latina no que tange à inibição e ao entorpecimento do processo de desenvolvimento. Por resultado, a estrutura social adquiriu um papel preponderante para a agenda da década de 1960 no estruturalismo de Prebisch e Furtado.

A questão do subdesenvolvimento da América Latina permaneceu como palco de debate para intelectuais como Celso Furtado e Raúl Prebisch. As discussões realizadas ao longo dos anos de 1970 tomam novas formas na década de 1970, quando o capitalismo passava por profundas transformações modificando as relações e formas de dependências. Conforme Pedrão (1998), a ascensão das transnacionais, que atuavam por fora das rédeas dos Estados nacionais, em conjunto com a concentração do capital financeiro mundial, refletiu em elevados níveis de endividamento dos países periféricos. O cenário indicou novamente a necessidade de novos moldes para o tratamento da questão do subdesenvolvimento.

A renovação do pensamento desses autores esteve imersa no ceticismo. Primeiro, Furtado incorpora o conceito de "dependência cultural", redesenhando a compreensão do fenômeno do subdesenvolvimento, levando-o a crer que o desenvolvimento havia se tornado um "mito" que prometia a possiblidade de 
universalizar o desenvolvimento dos países que lideraram a primeira revolução industrial; todavia, mesmo industrializados, a dependência tomava novas formas nos países periféricos (FURTADO, 1974). Prebisch - agora não mais com suas funções administrativas - consolidou a partir de uma série de textos uma nova abordagem para tratar das contradições do capitalismo periférico. Diante disso, o autor consolida uma proposta de transformação que se aproximava ao socialismo, alegando a necessidade em romper com os princípios que assentavam o capitalismo periférico (PREBISCH, 1981). Isso posto, conforme era alterada a situação da periferia - aprofundando os traços de dependência -, o pensamento de Furtado e Prebisch era renovado, trazendo novos diagnósticos, reflexões e receituários para tratar do fenômeno do subdesenvolvimento.

\section{Referências}

BIELSCHOWSKY, R. Pensamento Econômico Brasileiro: o ciclo ideológico do desenvolvimentismo. Rio de Janeiro: Contraponto, $2000 \mathrm{~b}$.

BIELSCHOWSKY, R. Prebisch e Furtado. In: GURRIERI, A. O Manifesto Latino-Americano e Outros Ensaios. Rio de Janeiro: Contraponto/Centro Internacional Celso Furtado, 2011.

BIELSCHOWSKY, R. Vinte Anos do IERJ, Cinquenta anos de CEPAL. In: POLETTO, D. W. (Org.). 50 anos do manifesto da CEPAL. Porto Alegre: EDIPUCRS, 2000a.

BUMER-THOMAS, V. La Historia Económica de América Latina desde la Independencia. México: Fondo de Cultura Económica, 2000.

CARMO SOBRINHO, C. A. Dependência e Estagnação: o debate sobre a crise dos anos 60. Campinas: Unicamp, 2001.

COUTO, J. M. Raúl Prebisch e a concepção e evolução do sistema centro-periferia. Revista de Economia Política, v. 37, n. 1, p. 65-87, 2017.

DOSMAN, E. Raúl Prebisch (1901-1986): a construção da América Latina e do Terceiro Mundo. Rio de Janeiro: Centro Internacional Celso Furtado de Políticas para o Desenvolvimento/Contraponto, 2011.

DUARTE, P. H. E.; GRACIOLLI, E. J. A Teoria da Dependência: interpretações sobre o (sub)desenvolvimento na américa latina. Colóquio Internacional Marx e Engels, Campinas, 2007. 
FONSECA, P. C. D.; SALOMÃO, I. C. Furtado vs. Prebisch: a Latin American Controversy. Investigación Económica, v. 77, n. 306, p. 74-93, 2018.

FURTADO, C. Desenvolvimento e Subdesenvolvimento. Rio de Janeiro: Contraponto: Centro Internacional Celso Furtado de Políticas para o Desenvolvimento, 2009 [1961].

FURTADO, C. Dialética do Desenvolvimento. Rio de Janeiro: Fundo da Cultura, 1964.

FURTADO, C. Entre Inconformismo e Reformismo. Revista de Economia Política, v. 9, n. 4, p. 6-28, 1989.

FURTADO, C. O Mito do Desenvolvimento Econômico. Rio de Janeiro: Paz e Terra, 1974.

FURTADO, C. Subdesenvolvimento e Estagnação na América Latina. Rio de Janeiro: Editora Civilização Brasileira, 1968 [1966].

GONÇALVES, L. E. F. C. As Relações Brasil-CEPAL (1947-1964). Brasília: Fundação Alexandre de Gusmão, 2011.

GUIMARÃES, J. A Trajetória Intelectual de Celso Furtado. In: Celso Furtado e o Brasil. TAVARES, M. C. (Org.). São Paulo: Editora Fundação Perseu Abramo, 2001.

GURRIERI, A. A Economia Política de Raúl Prebisch. In: GURRIERI, A. $O$ Manifesto Latino-Americano e Outros Ensaios. Rio de Janeiro: Contraponto/ Centro Internacional Celso Furtado, 2011.

HODARA, J. Prebisch y la Cepal: sustancia, trayectoria y contexto institucional. México: El Colegio de México, 1987.

LESSA, C. Apresentação. In: MALLORQUIN, C. Celso Furtado: um retrato intelectual. São Paulo: Xamã; Rio de Janeiro: Contraponto, 2005.

PEDRÃO, F. Evocação de Raúl Prebisch: latino-americano e homem do mundo. Centro Internacional Celso Furtado de Políticas para o Desenvolvimento, 2011.

PEDRÃO, F. O Significado da Revisão do Pensamento da Cepal. In: PEDRÃO, Fernando (Org.). O Pensamento da Cepal. Salvador: Organização dos Estados Americanos/Universidade Federal da Bahia/Ianamá, 1988. 
PINTO, A. Natureza e Implicações da "heterogeneidade Estrutural" da América Latina. In: BIELSCHOWSKY, R (Org.). Cinquenta Anos de Pensamento na Cepal. Rio de Janeiro: Editora Record, 2000.

POLLOCK, D. H. Raúl Prebisch Visto desde Washington: una percepcíon cambiante. Comércio Exterior, v. 37, n. 5, p. 366-370, 1987.

PREBISCH, R. Capitalismo Periférico: crisis y transformación. 1 ed. México: Fundo da Cultura Económica, 1981.

PREBISCH, R. Cinco Etapas de Mi Pensamento Sobre el Desarrolo. El Trimestre Económico. México, v. 2, n. 198, p. 1077-1096, 1983.

PREBISCH, R. Dinâmica do Desenvolvimento Latino-Americano. Rio de Janeiro: Fundo da Cultura, 1968 [1963].

PREBISCH, R. Nova Política Comercial para o Desenvolvimento. O Manifesto Latino-Americano e Outros Ensaios. Rio de Janeiro: Contraponto: Centro Internacional Celso Furtado, 2011a [1964].

PREBISCH, R. O Desenvolvimento Econômico da América Latina e alguns de seus principais problemas. In: GURRIERI, A. O Manifesto Latino-Americano e Outros Ensaios. Rio de Janeiro: Contraponto/Centro Internacional Celso Furtado, 2011c [1949].

PREBISCH, R. O Falso Dilema entre Desenvolvimento Econômico e Estabilidade Monetária. In: GURRIERI, A. O Manifesto Latino-Americano e Outros Ensaios. Rio de Janeiro: Contraponto/Centro Internacional Celso Furtado, 2011b [1961].

PREBISCH, R. Transformação e Desenvolvimento: a grande tarefa da América Latina. Rio de Janeiro: Fundação Getúlio Vargas, 1973 [1970].

RESENDE, A. L. Estabilização e Reforma: 1964-1967. In: ABREU. M. P. (Org.). A Ordem do Progresso: dois séculos de política econômica no Brasil. Rio de Janeiro: Elsevier, 2014.

RODRÍGUEZ, O. O Estruturalismo Latino-Americano. Rio de Janeiro: Civilização Brasileira, 2009.

ROSTOW. W. W. As etapas do Desenvolvimento Econômico. Rio de Janeiro: Zahar, 1974.

SERRA, J. Apresentação. In: Serra, J. (Org.). América Latina: ensaios de interpretação econômica. Rio de Janeiro: Paz e Terra, 1976. 
SERRA, J. Ciclos e Mudanças Estruturais na Economia Brasileira do Pós-Guerra. In: BELlUZZO, L. G. M; COUTINHO, R. (Org.). Desenvolvimento capitalista no Brasil: ensaios sobre a crise. Campinas: IE/Unicamp, v. 1, 1998. 